\title{
Estratégias metacognitivas na resolução de problemas verbais de matemática no ensino fundamental
}

Metacognitive strategies in the resolution of verbal problems of mathematics in fundamental teaching

Pablo Jovellano dos Santos Lima ${ }^{1}$

Marcia Gorette Lima da Silva ${ }^{2}$

Claudianny Amorim Noronha ${ }^{3}$

\section{Resumo}

A resolução de problemas no ensino de matemática é um assunto investigado nos últimos tempos, particularmente, no que se refere as distintas definições e dificuldades relacionadas ao seu tratamento em sala de aula. Neste artigo, buscamos discutir a importância da prática argumentativa na resolução de problemas verbais no ensino de matemática, principalmente, como pode contribuir para o desenvolvimento do pensamento metacognitivo. Em concreto buscamos inferir a partir dos discursos dos alunos, ao externalizarem suas ideias, possíveis estratégias metacognitivas durante a atividade de resolução de problemas matemáticos verbais. Para tal, realizamos uma investigação com sete alunos do $6^{\circ}$ ano do ensino fundamental de uma escola pública do Estado do Rio Grande do Norte, onde desenvolvemos atividades que promovessem discussões e debates em sala de aula, estimulando o uso da argumentação. A partir dos episódios transcritos dos debates entre os participantes foi possível identificar indícios da autorregulação do processo de aprendizagem, tais como questionamentos, emissão de opiniões, defesa de ideias e justificativa de escolhas. Entendemos que atividades dirigidas para fomentar a argumentação auxiliam na reflexão consciente contribuindo ao sujeito monitorar e controlar o seu entendimento, assim como suas dificuldades, permitindo-o confrontar ideias internamente, e, assim, agregar ou produzir novos conhecimentos.

Palavras chave: problemas verbais; educação matemática; estratégias metacognitivas; ensino fundamental

\section{Abstract}

Problem solving in mathematics teaching is a subject recently investigated, particularly with regard to the different definitions and difficulties related to its treatment in the classroom. In this article, we seek to discuss the importance of argumentative practice in solving verbal problems in mathematics teaching, especially how it can contribute to the development of metacognitive thinking. In concrete, we seek to infer from the students' discourses, when

\footnotetext{
1 Universidade Federal do Rio Grande do Norte I pabjovsan@yahoo.com.br

${ }^{2}$ Universidade Federal do Rio Grande do Norte | marciaglsilva@yahoo.com.br

${ }^{3}$ Universidade Federal do Rio Grande do Norte | cnoronha.ufrn@gmail.com
} 
externalizing their ideas, possible metacognitive strategies during the activity of solving verbal mathematical problems. To do this, we carried out an investigation with seven students from the 6th grade of a public school in the State of Rio Grande do Norte, where we developed activities that promoted discussions and debates in the classroom, stimulating the use of argumentation. From the transcribed episodes of the discussions among the participants, it was possible to identify indications of the self-regulation of the learning process, such as questioning, issuing opinions, defending ideas and justification of choices. We understand that activities aimed at promoting argumentation help in conscious reflection by helping the subject to monitor and control their understanding, as well as their difficulties, allowing them to confront ideas internally, and thus to aggregate or produce new knowledge.

Keywords: verbal problems; mathematics education; metacognitive strategies; elementary school

\section{Introdução}

Neste artigo ${ }^{\mathbf{4}}$, buscamos discutir a importância da prática argumentativa na resolução de problemas verbais no ensino de matemática, principalmente, no que refere à sua contribuição para o desenvolvimento do pensamento metacognitivo. Em concreto buscamos inferir a partir dos discursos dos alunos, ao externalizarem suas ideias, possíveis estratégias metacognitivas durante a atividade de resolução de problemas matemáticos verbais.

A opção pelo trabalho com a resolução de problemas se deu por ocasião do papel relevante que esta ocupa no ensino da matemática, seja como meio ou fim para/da aprendizagem. Neste sentido, preocupamo-nos com aspectos relacionados ao entendimento dos enunciados de problemas matemáticos verbais, a partir da prática da argumentação e de sua contribuição com o desenvolvimento do pensamento metacognitivo.

Para fins da pesquisa sobre a qual discorremos, compreendemos argumentação, a partir dos seus objetivos metacognitivos indicados por Erduran e Jiménez-Aleixandre (2007), como uma prática que possibilita os estudantes refletirem sobre as características dos conhecimentos a eles apresentados, solicitando-os a tomar decisões, assim como uma prática que permite o uso da consciência metaconceitual sobre, por exemplo, suas próprias ideias, suas concepções iniciais, os motivos e mudanças conceituais e as diferenças entre a posição inicial e final que vivenciam após uma sequência de ensino.

Dentre outros aspectos, compreendemos, portanto, que a argumentação trata de um movimento avaliativo que um sujeito realiza sobre o seu próprio conhecimento, tendo em vista o conhecimento do outro. Particularmente, neste estudo, a argumentação é utilizada como meio para o fomento a um ambiente no qual os alunos são estimulados a expressarem suas opiniões e defenderem suas ideias no uso de estratégias para resolver

\footnotetext{
${ }^{4}$ Esta pesquisa foi desenvolvida no âmbito do projeto "Linguagem e desenvolvimento sustentável: integrando ciências, língua portuguesa e matemática" e contou com o fomento do Programa Observatório da Educação, da Coordenação de Aperfeiçoamento de Pessoal de Nível Superior (CAPES).
} 
problemas, favorecendo o desenvolvimento de procedimentos metacognitivos relacionados às etapas desta resolução.

Em concreto, nosso estudo busca identificar estratégias metacognitivas expressas no discurso de alunos do $6^{\circ}$ ano do ensino fundamental durante a atividade de resolução de problemas matemáticos verbais. Para tal, desenvolvemos um desenho específico de pesquisa e a estruturação do ambiente com procedimentos metodológicos próprios.

Para fins deste artigo, apresentamos pontos importantes do referencial teórico adotado, especialmente no que refere aos eixos norteadores da pesquisa - resolução de problemas, metacognição e argumentação - e, posteriormente, descrevemos brevemente a estrutura organizacional da proposta e alguns dos acontecimentos vivenciados ao longo da intervenção realizada. Por fim, apresentamos algumas constatações decorrentes da análise dos dados coletados.

\section{Resolução de problemas em matemática: algumas características}

A resolução de problemas de matemática permeia algumas interpretações que são distintas entre si, fundamentando-se em concepções que apontam a relevância deste assunto para o ensino de matemática, destacando as mais comuns da resolução de problemas, a saber: meta; processo; habilidade básica ou metodologia para o ensino de matemática (BRANCA, 1997; D’AMBRÓSIO, 2003).

Entendemos que a resolução de problemas não pode ser visualizada como uma parte isolada no programa de matemática, ou seja, não é apenas uma meta a ser alcançada após ser trabalhado o conteúdo matemático ou uma habilidade básica que o sujeito precisa desenvolver para aprender matemática, muito menos um processo que precisa ser ensinado como sendo um conteúdo a parte. Assumimos que a resolução de problemas abrange estas perspectivas sendo compreendida como uma metodologia de ensino para a matemática.

Quando se aprende matemática e se busca aplicar os conceitos apreendidos em problemas relacionados a esta disciplina, a resolução de problemas é vista como uma meta. Contudo, ao fazer isso, entendemos que o próprio processo de resolução passa a contribuir para que os conceitos matemáticos sejam melhor compreendidos, passando a ser visto como uma habilidade básica que, ao ser desenvolvida pelo aluno, ajuda-o a ter melhores condições de aprender matemática. Todavia, para que a aprendizagem se efetive, é importante que o processo de resolução de problemas compreenda discussões que permitam aos alunos ter condições de justificar suas ideias e procedimentos realizados, a partir de um movimento discursivo que possa contribuir com o entendimento do conteúdo envolvido em torno das etapas de resolução (BRANCA, 1997; VAN DE WALLE, 2009).

No contexto desta pesquisa, assumimos por problema as frases, diagramas ou parágrafos curtos que incluem dados explícitos, que podem ser manipulados, comumente, utilizando um ou dois algoritmos.

Autores como Medeiros (2001) diferenciam problema não-verbal de verbal, sendo o primeiro aquele apresentado de modo sintetizado e com predomínio de termos matemáticos em seu enunciado, expressões do tipo "calcule" e "arme e efetue" são comuns neste tipo de problema. Tratam-se, portanto, de problemas que lidam com generalizações, 
com exercícios de fixação, sejam de definições, de fórmulas ou de procedimentos e não estão relacionados a contextos reais. O problema verbal, por sua vez, é aquele cujo enunciado se preocupa em contextualizar situações, com o predomínio de termos da língua materna (PONTE, 2003).

Em nossa investigação optamos em utilizar problemas do tipo verbal, não apenas por sua frequência nos livros didáticos e nas aulas de matemática, como também por implicarem, em seu processo de resolução, em estratégias como a leitura, a decodificação, a compreensão e a interpretação sobre a/as linguagem/ens neles inserida. Consideramos a classificação de Dante (2009) para apoiar a seleção dos problemas utilizados em nossa pesquisa, a saber:

Problemas-padrão: [...] são problemas que em sua resolução envolve a aplicação direta de um ou mais algoritmos anteriormente aprendidos e não exige nenhuma estratégia;

Problemas-padrão simples: [...] são problemas que podem ser resolvidos com uma única operação;

Problemas-padrão composto: [...] são problemas que podem ser resolvidos com duas ou mais operações;

Problemas-processo ou heurístico: [...] são problemas cuja solução envolve operações que não estão explicitamente no enunciado. Em geral, não podem ser traduzidos diretamente para a linguagem matemática, nem resolvidos pela aplicação automática de algoritmos, pois exigem do aluno um tempo para pensar e arquitetar um plano de ação, uma estratégia que poderá levá-lo à solução. Por isso, tonam-se mais interessantes do que os problemas-padrão (DANTE, 2009, p. 24-25, grifo do autor).

Tendo como base a classificação apresentada, planejamos uma intervenção que partia de problemas mais simples para os mais complexos e, por fim, encerramos as discussões com os problemas heurísticos, que se apresentam mais desafiantes para os alunos pelo fato de não terem uma operação/algoritmo aparente que permita ser utilizado para a sua solução.

A resolução de problemas com o grupo participante foi orientada de modo a estimular a discussão, a partir da perspectiva da argumentação, com vista ao desenvolvimento de estratégias metacognitivas, sejam estas conscientes ou não. Mas, que estratégias são essas e, como se relacionam com a resolução de problemas?

\section{Algumas considerações sobre metacognição e estratégias para resolução de problemas}

No campo da psicologia há autores que apresentam diferentes conceitos de metacognição. Por exemplo, Campione, Brown e Ferrara (1982, apud NEIMARK, DE LISI e NEWMAN, 1995) e Flavell (1981a, 1981b) referem-se a metacognição como o conhecimento do próprio conhecimento (dos processos cognitivos e de suas formas de operação) e como controle executivo que envolve a observação e manutenção do próprio comportamento; Cavanaugh e Perlmutter (1982), consideram metacognição como o conhecimento que o 
sujeito possui sobre seus processos cognitivos; e Lefebvre-Pinard e Pinard (1985) ressaltam o controle executivo.

Autores como Flavell (1981a, 1981b), Nelson e Narens (1996) e Sternberg (2000) consideram que a definição de metacognição abrange dois aspectos: o monitoramento do progresso cognitivo e o controle do nosso comportamento. O primeiro trata da capacidade que o sujeito possui para dirigir sua compreensão e avaliar o que foi aprendido. É o que faculta, por exemplo, o ato de planejar, selecionar, enfatizar, correlacionar e organizar. Para tanto, tal capacidade diz respeito ao conhecimento sobre o conhecimento, onde há tomada de consciência dos processos cognitivos e das competências necessárias para a realização de uma tarefa. Flavell (1979, citado por RIBEIRO, 2003, p.111), compreende este aspecto como

[...] o conhecimento ou crença que o aprendiz possui sobre si próprio, sobre os fatores ou variáveis da pessoa, da tarefa, e da estratégia e sobre o modo como afetam o resultado dos procedimentos cognitivos. Contribui para o controle das condutas de resolução, permitindo ao aprendiz reconhecer e representar as situações, ter mais fácil acesso ao repertório das estratégias disponíveis e selecionar as suscetíveis de se poderem aplicar. Permite, também, avaliar os resultados finais e/ou intermédios e reforçar a estratégia escolhida ou de a alterar, em função da feitura de avaliações.

O monitoramento metacognitivo abrange, por exemplo, o conhecimento que o sujeito possui sobre a natureza e os critérios de uma tarefa, assim como sobre as estratégias utilizadas para a efetivação da mesma. Ou seja, o sujeito possui a capacidade de reconhecer se a tarefa é ou não familiar, se está ou não bem organizada e se é difícil ou não. Assim, sabendo das características que a envolvem, o sujeito se esforça de forma proporcional a sua exigência. Este esforço envolve o uso de estratégias para a efetivação da referida tarefa, contudo, não bastará apenas tê-la e utilizá-la, mas também conhecer a sua especificidade e eficácia, sabendo adequá-la aos seus objetivos. Nesse sentido, Figueira (2003, p.4) comenta que

[...] Para dirigir e regular a sua própria cognição, o indivíduo tem de se conhecer a si próprio como processador de informação, isto é, ter consciência das suas características (por exemplo, saber que aprende melhor se ler em voz alta), conhecer as exigências da tarefa, isto é, a sua especificidade e finalidade e, de acordo consigo próprio e com a tarefa, escolher a estratégia que melhor conduza aos objetivos pretendidos.

Em síntese, este aspecto consiste em impressões e percepções conscientes que podem ocorrer antes, durante ou após a realização de uma tarefa. É por meio da capacidade de monitoramento que o sujeito avalia suas dificuldades, suas incompreensões e sentimentos e, consequentemente, desenvolve meios para lidar com tais situações.

O segundo aspecto que o conceito de metacognição contempla é o controle do nosso comportamento, de nossa postura frente a uma tarefa proposta. Ribeiro (2003) destaca que, 
em geral, não fazemos distinção entre controle e autorregulação, visto que ambos os movimentos partem da observação do próprio comportamento e de sua análise, a qual possibilita ao sujeito decidir se o mantém ou o modifica. Ou seja, tais denominações incutem no sujeito a capacidade para avaliar a execução de uma tarefa e fazer correções quando necessário. Existe, assim, o controle da responsabilidade dos processos que avaliam e orientam as operações cognitivas.

Na resolução de problemas, um bom resolvedor pode ser reconhecido como aquele que conseguiu desenvolver habilidades relacionadas às capacidades cognitivas, metacognitivas e afetivas subjacentes ao processo de resolução, como: a capacidade espacial, a capacidade lógica, a capacidade de leitura, a motivação, o interesse, a resistência aos bloqueios prematuros, a perseverança, a familiaridade com o contexto e o conteúdo do problema e a familiaridade com o domínio das estratégias de resolução (CHARLES; LESTER apud BORRALHO, 1994).

As habilidades cognitivas e afetivas, quando não bem desenvolvidas no sujeito, juntamente com a pressão e o stress, o qual possivelmente tenha que enfrentar ao lidar com um problema que Ihe traga alguma dificuldade. Podem Ihe influenciar negativamente no decorrer do processo de resolução, desse modo, é importante que se tenha consciência sobre a necessidade de monitorar e controlar, de modo ativo, as ações cognitivas e afetivas durante a tarefa proposta. A capacidade de monitoramento deste tipo de atividade está ligada à capacidade que o indivíduo tem de auto avaliar aquilo que faz, ou seja, monitorar sua performance, enquanto resolve um problema de matemática de acordo com uma dada instrução (CHARLES; LESTER apud BORRALHO, 1994)

Para Vieira (2001), o resolvedor de problemas matemáticos possui informações sobre seu próprio processo de resolução, o que the permite supervisionar o resultado ora encontrado. Considerando que há resolvedores de problemas de matemática experientes e, que há também os inexperientes, o autor ressalta que a diferença que há entre eles é que os primeiros concebem, de modo mais ágil o caminho mais adequado para solucionar problema. Estes se mostram mais habilidosos que os inexperientes para reconhecerem o que é importante no problema, descartando o que é irrelevante/acessório, abandonando, assim, as informações que nada tem a oferecer.

Van de Walle (2009, p.78), comenta que bons resolvedores de problemas possuem a capacidade de saber monitorar

[...] o seu pensamento de forma regular e automática. Eles sabem reconhecer quando estão presos ou não compreenderam completamente. Desse modo, tomam decisões conscientes para trocar de estratégias, repensar o problema, procurar conhecimentos de conteúdos relacionados que possam ajudar, ou simplesmente recomeçar.

Buscando associar tais posições com nosso objeto de estudo, entendemos que quando alguém, por exemplo: (a) volta a ler o problema ou passa a lê-lo em voz alta ou mesmo quando seleciona uma estratégia e a testa; (b) quando percebe falhas em seus procedimentos e volta a refletir sobre estes, tendo a possibilidade, assim, de optar por

\footnotetext{
${ }^{5} \mathrm{Na}$ literatura alguns autores fazem distinção entre autorregulação e controle, sendo o primeiro em que se observa e analisa o próprio comportamento, tendo consciência dos vários aspectos que o envolvem, buscando sempre sua manutenção. Já o segundo está mais relacionado à sua modificação quando há essa necessidade.
} 
novos caminhos de resolução, buscando se prevenir de novos erros; (c) quando compara os resultados obtidos com as informações contidas no enunciado do problema, dentre outras ações, tem-se, então, um sujeito que monitorou suas compreensões e seus resultados, que percebeu o que podia e o que não podia realizar, assim como percebeu também suas dificuldades iniciais e as decorrentes no processo de resolução e que controlou suas ações a partir destas percepções. Um sujeito que possui certo desenvolvimento metacognitivo não se dá por vencido ao ler o problema e não compreendê-lo e, estando motivado, passa a buscar estratégias que the permitam potencializar o seu processo cognitivo. Nesse movimento ele reavalia seu conhecimento e supervisiona sua resolução.

Nesta direção, há evidências, segundo Van de Walle (2009) de que o comportamento metacognitivo pode ser aprendido de modo a favorecer uma melhor resolução de problemas matemáticos. De acordo com o autor, alguns questionamentos podem orientar esse processo, a saber: "O que você está fazendo?", "Por que você está fazendo isso?" e "Como isto vai Ihe ajudar?". Explica ainda que tais perguntas não se configuram como uma receita única capaz de resolver o problema do aprendizado metacognitivo, mas que o mais importante é a ideia do questionar reflexivo. O autor comenta que o professor de matemática, ao buscar contribuir com o desenvolvimento do pensamento metacognitivo dos seus alunos, relacionado à resolução de problemas, pode

[...] fazer as perguntas quando se sentar para ouvir algum grupo. Reunindo-se com o grupo, você modela o questionamento que quer que os alunos eventualmente façam sozinhos. Nas séries finais do EF, cada grupo poderá designar um membro para ser o monitor. A função do monitor é a mesma de questionador reflexivo (do grupo) que você modelou enquanto trabalhava com o grupo (VAN DE WALLE, 2009, p. 78).

Segundo este ponto de vista, os estudantes podem ser auxiliados no desenvolvimento do seu pensamento metacognitivo, após a resolução do problema. Nesse caso, o professor estará contribuindo com o desenvolvimento de hábitos de monitoramento. O auxílio pode ser realizado por meio de uma breve discussão sobre as ações que foram tomadas/realizadas, pelos próprios alunos, durante a resolução do problema. Novos questionamentos podem ser realizados, entre eles: "O que você fez que lhe ajudou a compreender o problema? Você encontrou algum número ou informação que você não precisava? Como você decidiu o que fazer? Você analisou a resposta depois que a encontrou? Como você decidiu que sua resposta estava certa?" (ibid, 2009, p. 78). Para o autor, são questionamentos deste tipo que dizem aos alunos o que é importante observar nos problemas, estimulando-os a pensarem nestes questionamentos de antemão.

Partindo destas colocações, um dos aspectos a considerar é o estabelecimento de um ambiente favorável para que os estudantes possam expressar estas estratégias durante a resolução de problemas verbais. $E$, neste sentido, entendemos que $O$ ensino da argumentação pode favorecer o desenvolvimento do processo metacognitivo (JIMÉNEZALEIXANDRE, 2007). 


\section{Argumentação e resolução de problemas matemáticos}

Autores como Van Eemeren et al. (1996) destacam três tipos de argumentação: analítica, retórica e dialética. O primeiro se relaciona com a lógica formal, em que os argumentos $^{6}$ são produzidos preocupando-se apenas com sua estrutura lógica, considerando premissas dadas como verdadeiras para estabelecer uma conclusão, ou seja, a argumentação analítica utiliza-se de princípios universais para constituírem suas conclusões, as quais envolvem informações que já foram apresentadas (explícita ou implicitamente) nas razões (naqueles princípios/premissas) que a fundamentam. Os outros dois são ocasionados pelo raciocínio da lógica informal, a qual é "[...] um ramo da lógica encarregado de desenvolver padrões, critérios, procedimentos não-formais para a análise, a interpretação, a avaliação, a crítica e a construção de argumentos formulados em linguagem corriqueira" (JOHNSON e BLAIR, 1987 apud HEGENBERG; HEGENBERG, 2009, p.303). Esta linguagem é a que produz argumentos naturais, os quais exigem conhecimentos substanciais e intuitivos que não são analisados pelas regras da lógica formal. Em outros termos, a lógica formal se restringe a situações dedutivas utilizada, por exemplo, em demonstrações, enquanto a lógica informal a situações intuitivas como movimentos discursivos, dialógicos e comunicacionais.

Na lógica informal, portanto, predomina argumentos substanciais e intuitivos, os quais são argumentos práticos em que as conclusões envolvem informações que não são apresentadas nas razões que a fundamentam. Este tipo de argumento não pode ser validado (visto como uma verdade indubitável), mas pode ser admissível (visto como uma verdade aceitável). Os mesmos trazem-nos conclusões plausíveis por meio de justificativas que oferecem motivos para acolher tais conclusões. Estas justificativas são, geralmente, apoiadas em previsões, analogias, experiências, gestos, etc. Autores como Krummheuer (1995), indicam que estes tipos de justificativas são os mais utilizados nas aulas de matemática por estudantes do ensino básico, justamente por se relacionar mais com o convencer do que com a necessidade lógica das conclusões. Sobre estes dois tipos de argumentos Kolstø e Ratcliffe (2007, p.118) apontam que,

[...] Formas retóricas de argumentação referem-se a argumentos usados em situações monológicas onde um orador emprega técnicas discursivas, a fim de persuadir uma audiência. Em contraste, as formas dialéticas de argumentos estão envolvidas em diálogos entre dois ou mais debatedores [tradução nossa] ${ }^{7}$.

Segundo esses autores, aparentemente, pode-se dizer que o raciocínio informal compreende duas formas de argumentação: a individualista ou a social. Para eles, argumentos retóricos possuem natureza individualista, em que um único sujeito formula um

\footnotetext{
${ }^{6}$ Entendemos que a argumentação é constituída por um conjunto de elementos que possibilitam determinado sujeito auferir uma afirmação. Nesse sentido, é durante o processo da argumentação que os argumentos são produzidos. Argumentos, portanto, são as razões, justificativas e evidências que os sujeitos utilizam para chegar a uma conclusão.

${ }^{7}$ Rhetorical forms of argumentation refer to arguments used in monological situations where an orator employs discursive techniques in order to persuade an audience. In contrast, dialectical forms of arguments are involved in dialogues involving two or more discussants.
} 
ponto de vista diante de uma determinada plateia a fim de conseguir a adesão desta ao argumento proferido. Já os argumentos dialéticos possuem natureza mais social interacionista - referindo-se a uma disputa entre pessoas. Contudo, para Van Eemeren e Grootendorst (2004), qualquer tipo de argumento, seja ele retórico ou dialético, fará parte de um contexto social argumentativo. Quer dizer, mesmo que o argumento seja produzido individualmente/monologicamente, como no caso dos retóricos, o contexto poderá contribuir para debates imediatos ou futuros.

Tendo em vista os argumentos formais e os informais, Cabassut (2005) ao destacar a demonstração como um raciocínio válido que busca a verdade propriamente dita, indica que o argumento se propõe unicamente como um raciocínio que não obedece a restrições de validade, mas somente as que lhe são pertinentes, tendo como alvo a admissibilidade de uma assertiva. Sendo assim, Vignaux (1988) indica que a demonstração trabalha com premissas focalizando teoremas, enquanto que a argumentação trabalha com premissas prováveis dirigidas aos problemas. Afirma que mesmo havendo focos distintos, a argumentação e a demonstração se complementam/interpenetram em qualquer tipo de raciocínio. Desse modo, é possível dizer que as demonstrações se configuram como argumentos analíticos, tendo como fundamento a lógica formal, enquanto os outros tipos de argumentos (retórico e dialético) se configuram como substanciais construídos pela lógica informal. A base para estes argumentos serão, portanto, as justificativas (meios de convencimento) para se chegar a conclusão.

Krummheuer (1995), Cabassut (2005) e Boavida (2005) apontam que no processo argumentativo podem ser utilizados tanto elementos verbais quanto não-verbais nas justificativas produzidas, como, por exemplo, a fala, a produção de textos, o uso de imagens e de dados numéricos e até mesmo de gestos, principalmente no contexto da sala de aula. É neste movimento que se possibilita aos sujeitos envolvidos tornarem público seus raciocínios. Na escola, os alunos podem, assim, apresentar seus processos cognitivos, a partir da linguagem, de forma que os permitam explicar e avaliar, com mais clareza, este processo. Segundo Boero, Douek e Ferrari (2008) é nas argumentações dos alunos que se evidencia o uso intencional ou consciente das representações que fazem sobre os conceitos que estão sendo tratados nas aulas, revelando, assim, como estes são manipulados na intenção de se construir novos conhecimentos. É nos argumentos dos alunos, por exemplo, que as estratégias utilizadas para se atingir a solução de um dado problema de matemática, e que foi guardada para si, por aqueles, são explicitadas.

No Brasil, há estudos nesta perspectiva, por exemplo, Mello (2008) buscou compreender se o uso da argumentação em sala de aula contribui para a resolução de problemas, assim como também para o desenvolvimento dos processos metacognitivos envolvidos nesta resolução. O trabalho de Dantas (2010) teve como principal objetivo investigar a influência da argumentação matemática para a aprendizagem da resolução de problemas somente de estrutura aditiva com alunos da Educação de Jovens e Adultos dos anos iniciais do Ensino Fundamental. Stock (2015) investigou como a argumentação pode contribuir para o ensino e a aprendizagem de conceitos matemáticos a partir da resolução de problemas.

Os estudos ora mencionados apresentam em comum a relação entre a resolução de problemas matemáticos e a argumentação. É nesse viés que apoiamos nossa pesquisa, isto é, considerando a potencialidade desta relação para favorecer a promoção do acesso pelos 
alunos aos processos cognitivos e metacognitivos, ou seja, à oportunidade de aprender como aprender.

\section{Procedimentos metodológicos}

O estudo do tipo etnográfico aqui apresentado foi desenvolvido com sete alunos do $6^{\circ}$ ano do ensino fundamental de uma escola pública do Estado do Rio Grande do Norte. A intervenção foi aplicada por um dos autores desta pesquisa, no contra turno das aulas de uma turma de vinte e cinco alunos, sendo que apenas sete alunos concordaram em participar, apresentando o termo de compromisso livre e esclarecido assinado pelos pais e/ou responsáveis legais. No termo constavam os objetivos e horários das atividades de pesquisa, além do compromisso de não identificação dos participantes. Deste grupo, quatro possuíam as piores notas em matemática.

A intervenção teve duração de três meses e a coleta de dados foi registrada por gravações em áudio e vídeo; por registro escrito em diários de campo pelo pesquisador e nas próprias atividades respondidas pelos alunos. As produções escritas, orais e gestuais coletadas ao longo da intervenção foram transcritas e analisadas na perspectiva da Análise Textual Discursiva (ATD) que, conforme Moraes (2003), transita por dois modos de análise de pesquisa qualitativa: a análise de conteúdo e a análise de discurso. Compreendemos que a ATD se aproxima mais da análise de conteúdo, contudo busca reconstruir significados mais complexos e aprofundados, a partir dos discursos expressos.

Moraes e Galiazzi (2006) indicam que esse tipo de análise exige que o pesquisador se torne sujeito em seu campo de investigação e assuma suas próprias interpretações. Para que a ATD seja posta em prática, faz-se necessário haver um conjunto de produções textuais, ou seja, o corpus da pesquisa (o material verbalizado pelos sujeitos participantes), para que o próprio pesquisador possa mergulhar a fim de compreendê-lo, desconstruindoo e reconstruindo-o, buscando resultados que o permita obter respostas para os objetivos traçados na pesquisa.

A partir deste corpus da pesquisa, como primeira etapa para o desenvolvimento da ATD, tem-se o processo denominado unitarização. Este processo implica em "desmembrar" o texto (produzido pelos sujeitos participantes) em partes chamadas de unidades elementares de significados, os quais discriminam significados importantes para a finalidade da pesquisa. Tais unidades são recortes do texto original que passaram pela capacidade interpretativa do pesquisador, o qual relacionou a ideia presente no recorte com o tema em investigação. Tendo decorrido a etapa da unitarização, parte-se para a segunda etapa: a categorização. Nesta, visa-se construir relações entre as unidades elementares de significados. Intencionando maior compreensão sobre o que vem sendo observado nas unidades, o propósito desta vez é comparar, combinar e classificar as mesmas buscando a formação de conjuntos mais complexos, as categorias. Em nosso caso, estabelecemos as categorias a priori, o que também se permite nesse tipo de análise, e, a partir destas categorias, buscamos identificar as unidades elementares de significados. Tendo esses dois movimentos realizados, iniciamos o terceiro e último passo da ATD: a construção de um metatexto. Trata-se de um processo de explicitação sobre os movimentos realizados. Isto é, um texto que descreva de modo sucinto e compreensivo a interpretação dada ao fenômeno observado. 


\section{Resultados}

Na investigação buscamos identificar as estratégias de leitura, os elementos estruturantes de um problema verbal (questão principal e condicionantes), a seleção da estratégia e de validação dos resultados obtidos pelos alunos no processo de resolução de problemas verbais. Em seguida, passamos a identificar as unidades elementares de significados tanto no processo discursivo quanto no processo de análise sobre os dados coletados, baseados nas categorias já pré-estabelecidas, a partir das etapas que compõem a resolução de um problema verbal (VAN DE WALLE, 2009; SUYDAM, 1997). As unidades pré-estabelecidas em nossa investigação e as respectivas categorias foram:

\begin{tabular}{|c|c|}
\hline Categorias & Ações \\
\hline $\begin{array}{l}\text { Procedimentos de } \\
\text { leitura }\end{array}$ & $\begin{array}{c}\text { ler mais de uma vez; } \\
\text { ler em voz alta; } \\
\text { ler de modo mais lento; } \\
\text { criar hipóteses para a compreensão do problema. }\end{array}$ \\
\hline $\begin{array}{l}\text { Identificação dos } \\
\text { elementos de um } \\
\text { problema verbal }\end{array}$ & $\begin{array}{c}\text { pontuação gráfica; } \\
\text { identificação a partir do contexto; } \\
\text { síntese a partir de sua questão central; } \\
\text { identificação das informações necessárias para responder a questão central; } \\
\text { presença de dados numéricos ou inferidas a partir de outras ou da questão } \\
\text { central; } \\
\text { utilizar uma estratégia conhecida. }\end{array}$ \\
\hline $\begin{array}{c}\text { Resolução do } \\
\text { problema e } \\
\text { estratégias utilizadas } \\
\text { na validação dos } \\
\text { resultados }\end{array}$ & $\begin{array}{l}\text { uso de operação matemática para validar resultado obtido por meio de outra } \\
\text { operação; } \\
\text { uso de uma operação como estratégia de resolução indicando outra } \\
\text { operação para o mesmo fim; } \\
\text { resença de palavras/expressões como pistas para identificar a operação a ser } \\
\text { realizada; } \\
\text { qualquer informação que faça parte do problema utilizada para resolvê-lo; } \\
\text { validar o resultado a partir de uma hipótese apresentada por outro sujeito }\end{array}$ \\
\hline
\end{tabular}

Quadro 1 - Categorias e unidades de ação que emergiram da pesquisa.

$\mathrm{Na}$ etapa das discussões, os alunos foram convidados a participar desse movimento emitindo suas opiniões e justificando suas ideias. Ao professor coube a tarefa de instigá-los a apresentar explicações sobre suas escolhas, sempre atento a alguma indicação sobre o procedimento utilizado durante a resolução do problema. Desse modo, considerando as intervenções do professor, assim como, a participação dos alunos, foi possível inferir a ocorrência dos processos metacognitivos.

As ações indicadas no Quadro 1 configuram como estratégias metacognitivas e se apoiam nos estudos de Ribeiro (2003) e Flavell (1987) ao entender que tais ações contribuem, em alguma medida, com a resolução de um problema verbal matemático. Isto é, podem consistir em ações que tiveram como objetivo potencializar/vivificar o monitoramento de seu próprio progresso cognitivo. Para este artigo, apresentamos a seguir três episódios. O primeiro exemplifica uma das ações apresentadas no quadro 1, sendo: validar o resultado a partir de uma hipótese apresentada por outro sujeito referente à categoria Resolução do problema e estratégias utilizadas na validação dos resultados. 0 segundo e o terceiro exemplificam outras situações que também foram observadas em 
nossas análises e, que também dizem respeito ao processo de monitoramento metacognitivo.

No primeiro episódio, a discussão se deu em torno do problema apresentado na atividade 6, a seguir:

Atividade 6: Uma professora recebeu quinze livros. Deu alguns para seus alunos e depois recebeu mais três livros, ficando com oito livros. Quantos livros a professora deu para seus alunos?

Para a discussão desse problema, os alunos foram separados em dois grupos com três componentes cada. Após algum tempo de discussão entre si, um dos alunos (Alex) apresentou dificuldades para compreender o problema, sendo então auxiliado por outro aluno (Aline), a qual, de fato, havia resolvido corretamente o problema. Mesmo com esse auxílio, Alex entende que a resposta para o problema seria cinco livros doados pela professora, quando a resposta correta são 10 livros doados.

Em um dado momento, o professor solicita que Alex explique seus resultados. Ele então, indica que a resposta é "cinco para cada", ou seja, que os alunos dessa professora devem receber 5 livros, cada um. O aluno Jonathan, ao escutar essa indicação, toma a mesma para si e passa a explicar que o número 10 surge devido a professora ter 3 alunos (sua hipótese). É importante salientar que Jonathan também esteve presente nas explicações de Aline. É possível neste contexto que tenha ocorrido uma compreensão do problema sem, no entanto, chegar ao resultado final. Talvez porque para este participante, já que se deve dar 5 livros para cada aluno (resposta de Alex), então, o número 10 refere-se a uma quantidade que deve ser distribuída para dois outros alunos. O trecho a seguir mostra Jonathan fornecendo essa indicação ao professor:

Professor: Ela tinha 2 alunos? Onde é que tá dizendo isso... 2 alunos?

Jonathan: Não... Isso é o que eu imagino!

Professor: Você tá imaginando que têm 2 alunos? Por que tá imaginando que têm 2 alunos?

Jonathan: Porque... se ela tem 15 livros... aí recebia 5... porque ela tinha 2 alunos pra dar 5 pra cada um... E mais 1... Eu acho que tem mais 1... Pra dar... [Percebe-se que o aluno conclui haver 3 sujeitos no total, já que são 15 livros a serem doados]

Professor: Certo... Então... Por que são 10? [professor aponta a folha de respostas do Jonathan]

Jonathan: Porque tinham 2 alunos (...)

Entendemos que as explicações e justificativas dos seus parceiros de grupo e os questionamentos do professor contribuíram para que 0 aluno monitorasse o seu entendimento sobre o problema, assim como as suas dificuldades. Jonathan entendeu que o número 10 serviu como resposta a partir das explicações de Aline. Ele constata tal solução refazendo oralmente, em um dado momento, as contas que Aline explicou. Porém, algumas dúvidas ainda o acometeram e ele as percebe a partir das discussões, as quais o instigaram a refletir novamente sobre o resultado encontrado. Desse modo, ao monitorar sua compreensão sobre o referido resultado, ele percebe sua dificuldade (como foi obtido o 
número 10 como resposta?) e passa a controlar suas ações, sem deixar de monitorá-las (já que diz que há 2 alunos e talvez mais 1, devido a quantidade total de livros ser 15 e considerando que cada aluno deve receber 5) utilizando, assim, a hipótese levantada por Alex para finalmente validar o resultado encontrado.

O segundo episódio parte de uma situação onde o professor, para promover discussões em sala de aula, a partir de um determinado problema ${ }^{8}$, escreve no quadro duas soluções apresentadas por dois alunos para o problema da Atividade 4, exposta a seguir:

Atividade 4: Nei vem juntando dinheiro há 5 meses. Durante cada mês ele guardou na poupança uma quantia de $R \$ 190,00$. Com esse dinheiro ele comprou um aparelho de som por $R \$ 635,00$ duas caixas de som por $R \$ 128,00$ cada uma e também pagou $R \$ 12,00$ pela instalação do som. Qual a quantia que ele gastou?

Uma das respostas expostas pelo professor apresentava uma estratégia de solução incorreta, onde o aluno subtrai cada valor gasto do valor total juntado pelo personagem do problema. A outra resposta exposta pelo professor, por sua vez, apresenta uma estratégia de resolução correta, com a adição de todos os gastos indicados no problema.

O que se percebe durante as discussões é que o aluno que apresentou a estratégia incorreta como solução para o problema, se baseou na palavra "gastou" que compõe a pergunta do problema. Ao longo da discussão sobre as respostas expostas, dois outros alunos passam a concordar com a resposta incorreta, considerando também a existência unívoca da relação gastou-subtração. O episódio deste movimento discursivo é transcrito a seguir:

Professor': Ó... O Jorge falou o seguinte então... Ele falou que somou... Porque ele quis saber quanto gastou... E depois diminuiu pra saber quanto sobra... Marcos por que você diminuiu? [professor aponta o quadro] Por que você saiu diminuindo?

Jonathan: Eu acho que eu sei.

Alex: Por que... ele gastou?

Jonathan: Porque tem que diminuir cada parte de... Cada um que ele gastou... E cada parte dessa daí são de mais... É quase igual a menos.

Professor: Como é que é?

Jonathan: Cada parte que tem... É de menos... Essa de menos... Tá dizendo... 900 menos... [o aluno corrige] 950 menos 635... Vai dar 30... 315... Esse 315 ele diminuiu... Essa diminuição deu correta... Pra mim... [Pausa de 3 segundos pensando] então agora eu tô confiando mais em Jorge que essa conta aí é de mais...

8 Os problemas foram retirados e adaptados do sitio <https://saberceec.wordpress.com/2012/07/04/90problemas-matematicos-para-o-6o-ano-2/>

${ }^{9}$ Os nomes dos alunos citados neste trabalho são fictícios, seus nomes verdadeiros foram preservados devido ao acordo estabelecido no Termo de Consentimento Livre e Esclarecido - TCLE assinado pelos pais destes alunos. 
Neste episódio o professor busca identificar o porquê do uso da subtração na resposta do Marcos (a resposta incorreta). Percebe-se também que Alex confirma a estratégia de subtração informando que esta se deu devido aos gastos realizados pelo personagem do problema. Mas, o que nos chamou mais a atenção foram as tentativas de explicações pelo Jonathan. Este aluno, durante toda a discussão, defendeu a resposta do Marcos para a resolução, contudo, aos poucos foi demonstrando certa concordância com a resposta do outro aluno, a correta.

Na primeira participação de Jonathan é possível perceber que, apesar de indicar que se deve diminuir os valores gastos, comenta que a conta a ser realizada é de "mais" (se referindo a adição). Porém, logo em seguida, ele se "prende" novamente a subtração. Em sua segunda participação, o aluno defende a ideia da subtração. Mas, posteriormente, ele passa a concordar com a resposta do aluno que apresentou a solução com a adição. Temos, portanto, um aluno que passa a refletir sobre o problema durante a discussão, coisa que não fez em uma primeira leitura. A partir dos questionamentos do professor e das contribuições de seus pares, o aluno retoma, constantemente, o problema. Em sua confusão de ideias, ele passa a refletir, a se questionar e a perceber suas dificuldades, ou seja, ele monitora, assim, suas compreensões e passa a tentar controlar suas próprias ações, revezando entre suas falas e reflexões.

O terceiro episódio aborda dois problemas do tipo heurístico. O primeiro (atividade 9) contemplou uma situação na qual a ordem das informações foi apresentada de modo invertido, ou seja, para resolver o problema o sujeito deveria, primeiro, se apropriar do último dado informado no enunciado e relacioná-lo com o dado anterior, fazendo isso sucessivamente. Vejamos o primeiro problema ${ }^{10}$.

Atividade 9: Três pessoas chamaram o elevador. Lucas foi o primeiro a entrar, o elevador desceu 6 andares e entrou a Maria. Depois o elevador subiu 8 andares e entrou o José. Desceu 6 andares e parou no $4^{\circ}$ andar. Em qual andar cada uma das pessoas entrou no elevador?

Já no segundo problema ${ }^{11}$ (atividade 10) não houve essa necessidade, tendo, então, a ordem de suas informações não invertidas.

Atividade 10: Cérbero é um monstruoso cão de 3 cabeças da mitologia grega. Cada vez que uma das suas cabeças está doendo, ele tem que tomar quatro comprimidos. Hoje as suas três cabeças tiveram dor. Mas o frasco já estava no fim e ficou faltando comprimidos para uma cabeça. Quantos comprimidos haviam no frasco?

Durante as discussões relativas ao segundo problema, o professor questiona os alunos acerca do entendimento do referido problema, comparando a dificuldade deste com o problema anterior. Observemos esse episódio:

Professor: Compreenderam o problema? [Os alunos confirmam que sim] Foi mais fácil ou difícil que compreender o outro?

Aline: Mais fácil.

Alex: Mais fácil para entender.

\footnotetext{
${ }^{10}$ Extraído e adaptado de Carvalho (2012).

${ }^{11}$ Extraído e adaptado de Stancanelli (2001).
} 
Jorge: Precisei nem de cálculo professor.

Jonathan: Foi mais fácil... Porque o outro eu tive que ler um pouco de trás pra frente... De trás pra frente e pra trás [O aluno faz gestos com as mãos em um movimento de ida e volta]

Professor: Peraí... Calma... É o que Jonathan?

Jonathan: Esse aqui foi mais fácil porque o outro tive que ler de trás... Aí eu tentei dá uma olhada pro problema lá... [O aluno repete os gestos, movimentando as mãos para trás e para frente]. Mas, eu tô complicado com aquela conta.

Jorge: What?

Professor: Você tentou também ler este de trás pra frente?

Jonathan: Tentei

Neste trecho, o aluno Jonathan indica que o problema da atividade 10 foi mais fácil de compreender que o da atividade 9, pois não houve necessidade de lê-lo de "trás pra frente" como afirmou o aluno. Comenta que "olhou o problema lá", ou seja, ele voltou a visualizar o problema anterior e tentou realizar o mesmo procedimento de leitura. Compreendemos que tal ação se deu em uma tentativa de compreender o enunciado.

Dessa forma, ele ao monitorar a sua compreensão busca controlar suas ações utilizando um procedimento já realizado em outra ocasião. Destacamos que o referido procedimento foi bastante discutido pelos alunos, possibilitando sua internalização. O que nos leva a inferir que alguns aspectos discutidos durante a resolução de um problema podem auxiliar os alunos, em seus monitoramentos, em ocasiões posteriores.

\section{Considerações finais}

Ao investigar a importância da argumentação no ensino de matemática, foi possível identificar algumas evidências de que a participação em atividades de resolução de problemas matemáticos de determinados tipos contribui para o desenvolvimento de habilidade metacognitivas de estudantes de turmas do $6^{\circ}$ ano do ensino fundamental. Nas discussões promovidas durante a intervenção didática proposta, notamos que tanto o professor quanto os alunos participantes, ao questionarem, emitirem suas opiniões e justificarem suas escolhas, demonstraram indícios desse desenvolvimento.

Os episódios apresentados neste artigo, assim como outros ocasionados em nossa investigação, permitiram-nos compreender que durante as discussões ocorrem situações em que os sujeitos, mesmo que momentaneamente, "assumem" algo dito pelo outro, tomando uma ideia/concepção, deste outro, como uma verdade, sem mesmo ter descartado a sua concepção original. Ao fazer isso, através de algum processo interno que Ihes ocorrem, esta nova ideia/concepção pode ser descartada ou não, cabendo a estes sujeitos decidirem se externalizam ou não o que está sendo experimentado. Trata-se, portanto, de uma situação onde ocorre o monitoramento e o controle do processo cognitivo, sem que haja, necessariamente, a produção de um novo conhecimento, que 
possibilita o fortalecimento/amadurecimento de uma ideia/concepção, a validação de um resultado e a explicação de alguma escolha, além de contribuir para uma melhor compreensão do outro.

Além disso, concluímos também que estratégias de leitura, de resolução e de validação, quando discutidas, parecem auxiliar os alunos em seus monitoramentos e controles em momentos futuros, contribuindo, portanto, com o desenvolvimento dos seus pensamentos metacognitivos.

\section{Referencias}

BRANCA, N. A. Resolução de problemas como meta, processo e habilidades básica. In: KRULIK, S.; REYS, R. (org.). A Resolução de problemas na matemática escolar. São Paulo: Atual, p. 4-12. 1997.

BOAVIDA, A. M. R. A argumentação em Matemática Investigando o trabalho de duas professoras em contexto de colaboração. 2005. 975 f. Tese (Doutorado em Educação) Faculdade de Ciências, Universidade de Lisboa, 2005.

BOERO, P.; DOUEK, N.; FERRARI, P. L. Developing mastery of natural language. In L. English (ed.) International Handbook of Research in Mathematics Education. New York: Routledge, p.262-295. 2008.

BORRALHO, A. M. Aspectos metacognitivos na resolução de problemas de matemática: proposta de um programa de intervenção. 1994. Dissertação (Mestrado em Tecnologia da Educação). Universidade de Évora, Portugal, 1994.

CABASSUT, R. Demonstration, raisonnement et validation dans l'enseignement secondaire des mathematiques en france et en alle-magne. 2005. $527 \mathrm{f}$. Tese (Doutorado em didática da matemática) - Ecóle doctorale Savoir scientifique: épistémologie, histoire des sciences, didactique des disciplines. Université Paris 7, Paris, 2005.

CARVALHO, M. Problemas? Mas que problemas? Estratégias de resolução de problemas matemáticos em sala de aula. 5ª ed. Petrópolis: Vozes, 2012.

CAVANAUGH, J. C.; PERLMUTTER, M. Metamemory: A critical examination. Child Development, v. 53, p.11-28. 1982.

D'AMBROSIO, B. S. Teaching Mathematics through Problem Solving: A Historical Perspective. In: SCHOEN, H. L. (ed.) Teaching Mathematics through Problem Solving: grades 6-12. Reston: NCTM, cap.4, p.39-52. 2003

DANTAS, J. B. A argumentação matemática na resolução de problemas de Estrutura aditiva com alunos de EJA. 2010. 144f. Dissertação (Mestrado em Educação) - Universidade Federal de Pernambuco, 2010.

DANTE, L. Formulação e resolução de problemas de matemática. São Paulo: Ática. 2009.

ERDURAN, S.; JIMÉNEZ-ALEIXANDRE, M. P. Argumentation in Science Education: An Overview. In: ERDURAN, S.; JIMÉNEZ-ALEIXANDRE, M. P. (eds.). Argumentation in Science Education: Perspectives from Classroom-Based Research. Dordrecht: Springer, p.3-28, 2007. 
FIGUEIRA, A. P. C. Metacognição e seus contornos. Revista Iberoamericana de Educación, OEI, p. 1-20, 2003. Disponível em: <http://www.rieoei.org/deloslectores/446Couceiro.pdf>. Acesso em: 20/dez/2017.

FLAVELL, J. H. Cognitive monitoring. In: W. P. Dickson (org.). Children's oral communication skills. New York: Academic Press, p.35-60. 1981a.

FLAVELL, J. H. Metacognition and cognitive monitoring: a new area of cognitivedevelopmental inquiry. In: H. Parke (Org.). Contemporary readings in child psychology. New York: McGraw Hill, p.165-169. 1981b

FLAVELL, J. H. Speculations about the nature and development of metacognition. In F. E. WEINERT; R. H. KLUWE (eds.), Metacognition, motivation and understanding (p. 21-29). Hillsdale: Lawrence Erlbaum Associates. 1987.

FRY, P. S.; LUPART, J. L. Cognitive processes in children's learning. Springfield: Charles C. Thomas.1987.

HEGENBERG, L.; HEGEMBERG, F. Argumentar. Rio de Janeiro: E-papers, 2009.

JIMENEZ-ALEIXANDRE, M. P. Designing Argumentation Learning Environments. In: ERDURAN, S.; JIMENEZ-ALEIXANDRE, M. P. (eds.). Argumentation in Science Education: perspectives from classroom-based research. Dordrecht: Springer, p.91-115. 2007

JOHNSON, R.; BLAIR, J. The current state of informal logic. Informal logic, v. 9, p.147-151. 1987

KOLSTØ, S. D.; RATCLIFFE, M. Social Aspects of Argumentation. In: ERDURAN, S.; JIMENEZALEIXANDRE, M. P. (eds.). Argumentation in Science Education: Perspectives from Classroom-Based Research. Dordrecht: Springer, 2007, p.116-136.

KRUMMHEUER, G. The ethnography of argumentation. In: COBB; BAUERSFELD (eds.), The emergence of mathematical meaning: interaction in classroom cultures, NY: Erlbaum, p.229269. 1995.

LEFEBVRE-PINARD, M.; PINARD, A. Taking charge of one's cognitive activity: A moderator of competence. In: NEIMARK, R.; NEWMAM, J. (org.). Moderators of competence. Hillsdale, N.Y.: Erlbaum, p.191-212. 1985.

MEDEIROS, C. F.; Modelos mentais e metáforas na resolução de problemas de matemática verbais. Ciências \& Educação, v. 7, n. 2, p. 209-234. 2001.

MELLO, T. A. Argumentação e metacognição na solução de problemas aritméticos de divisão. 2008, 338 p. Dissertação (Mestrado em Educação). Universidade Estadual de Campinas, Faculdade de Educação, Campinas, SP.

MORAES, R. Uma tempestade de luz: a compreensão possibilitada pela análise textual discursiva. Ciência \& Educação, v.9 n.2, p.191-211, 2003.

MORAES, R.; GALIAZZI, M. C. Análise textual discursiva: Processo reconstrutivo de múltiplas fases. Ciência \& Educação, v. 12, n. 1, p. 117-128, 2006.

NEIMARK, E.; LISI, R.; NEWMAN, J. L. Moderators of competence. NY: Erlbaum, 1995.

NELSON, T.; NARENS, L. Why investigate Metacognition? In:METCALFE; SHIMAMURA (eds.) Metacognition: knowing about knowing. Cambridge, MA: MIT Press, p.1-27. 1996. 
PONTE, J. P. Investigar, ensinar e aprender. In: Actas do ProfMat. Lisboa: APM, p. 25-39, 2003.

RIBEIRO, C. Metacognição: Um apoio ao processo de aprendizagem. Psicologia: Reflexão e Crítica, v. 16, n. 1, p.109-116. 2003.

STANCANELLI, R. Conhecendo diferentes tipos de problemas. In: SMOLE, K. S.; DINIZ, M. I. (Orgs.). Ler escrever e resolver problemas: habilidades básicas para aprender matemática. Porto Alegre: Artmed, 2001.

STERNBERG, R. Psicologia cognitiva. Porto Alegre, RS: Artes Médicas, 2000.

STOCK, S.B. A argumentação na resolução de problemas de Matemática: uma análise a partir da Epistemologia Genética. 2015, 182 f. Dissertação (Mestrado em Educação). Universidade Federal do Rio Grande do Sul, 2015.

SUYDAM, M. N. Desemaranhando pistas a partir da pesquisa sobre resolução de problemas. In: KRULIK, S.; REYS, R. E. (org.). A Resolução de problemas na matemática escolar. São Paulo: Atual, p. 49-73, 1997,

VAN DE WALLE, J. A. Matemática no Ensino Fundamental: formação de professores e aplicação em sala de aula. 6 ed. Porto Alegre: Artmed, 2009.

VAN EEMEREN, F. H. et al. Fundamentals of argumentation theory: A handbook of historical backgrounds and contemporary developments. Mahwah, NJ: Lawrence Erlbaum, 1996.

VAN EEMEREN, F. H.; GROOTENDORST, R. A systematic theory of argumentation. Cambridge: University press, 2004.

VIEIRA, E. Representação mental: as dificuldades na atividade cognitiva e metacognitiva na resolução de problemas matemáticos. Psicologia Reflexiva e Crítica, v. 14, n. 2, 2001. 